\begin{tabular}{|c|c|c|c|c|}
\hline JURNAL & VOLUME 1 & NOMOR 1 & HALAMAN 1-70 & $\begin{array}{r}\text { ISSN 2655-8823 }(p) \\
\text { ISSN - }(e)\end{array}$ \\
\hline
\end{tabular}

\title{
KONFLIK LAHAN MEGA PROYEK BENDUNGAN LEUWIKERIS DI DESA ANCOL KECAMATAN CINEAM KABUPATEN TASIKMALAYA
}

\author{
Rini Rizkiawati, \\ Mahasiswa Program Studi Kesejahteraan Sosial FISIP UNPAD \\ E-mail: rizkiarini23@gmail.com \\ Sahadi Humaedi \\ Dosen Program Studi Kesejahteraan Sosial FISIP UNPAD \\ E-mail: sahadi.humaedi@unpad.ac.id
}

\begin{abstract}
ABSTRAK
Konflik merupakan aspek alami dalam suatu kehidupan sosial bermasyarakat yang tidak bisa dielakkan dalam kehidupan manusia. Konflik yang timbul disuatu masyarakat tentunya memiliki suatu dampak positif dan negatifnya dan sering membuat kondisi menjadi tidak nyaman.. Seperti halnya konflik yang terjadi di Desa Ancol Kabupaten Tasikmalaya terkait pembangunan bendungan Leuwikeris. Konflik tersebut terjadi karena adanya rasa ketidakadilan dan kecemburuan terhadap harga jual tanah yang memiliki ketimpangan cukup tinggi dengan Kecamatan Ciamis. Hal tersebut tentunya mampu memperungaruhi kondisi sosial dan ekonomi masyarakat. Jika meninjau pada teori transformasi konflik menurut Fisher dkk, berasumsi bahwa konflik mengenai pembangunan bendungan tersebut disebabkan oleh masalah-masalah ketidaksetaraan dan ketidakadilan yang muncul sebagai masalah-masalah sosial, budaya, dan ekonomi.
\end{abstract}

Kata Kunci: Konflik, Bendungan Leuwikeris, Teori Transformasi Konflik

\begin{abstract}
Conflict is a natural aspect of a social life that is inevitable in human life. Conflicts that arise in a community certainly have a positive and negative impact and often make conditions uncomfortable. As with the conflict that occurred in Ancol Village, Tasikmalaya Regency, related to the construction of the Leuwikeris Dam. The conflict occurred because of a sense of injustice and jealousy towards the selling price of land that had quite high inequality with the Ciamis District. This is certainly able to influence the social and economic conditions of the community. If you look at the theory of conflict transformation according to Fisher et al., It is assumed that conflicts regarding dam construction are caused by problems of inequality and injustice that arise as social, cultural and economic problems.
\end{abstract}

Keywords: Conflict, Leuwikeris Dam, Conflict Transformation Theory

\section{PENDAHULUAN}

Pada dasarnya kita ketahui ketika suatu daerah melakukan suatu pembangunan tentunya hal tersebut diharapkan memiliki suatu dampak positif untuk meningkatkan kesejahteraan masyarakat di sekitarnya. Namun, pada kenyataannya dalam suatu pembangunan yang dilakukan di setiap daerah terkait dengan pembebasan lahan seringkali terjadi suatu konflik yang tentunnya berdampak besar kepada masyarakatnya. Seperti halnya konflik lahan yang terjadi di Desa Ancol Kecamatan Cineam Kabupaten Tasikmalaya, antara warga dan pemerintah setempat yang melakukan pembebasan lahan untuk proyek Bendungan Leuwikeris. Konflik tersebut terjadi karena masyarakat merasa tidak mendapatkan suatu keadilan terkait pembebasan lahan. Warga yang menjual tanahnya yang terkena dampak pembangunan Bendungan Leuwikeris 
merasa mengalami kerugian dikarenakan tidak ada sosialisasi pembebasan tanah terlebih dahulu. Hal tersebut tentunya berpengaruh terhadap kondisi sosial dan ekonomi dari warga yang menjual tanah tersebut. Pada kenyataannya pemerintah setempat langsung melakukan penetapan harga. Warga tidak mempunyai pilihan selain jalur pengadilan, mereka pun ditakut-takuti. Sehingga pada akhirnya mereka pun mau tidak mau menerima uang tersebut sesuai penetapan harga oleh pemerintah setempat tanpa ada sosialisasi terlebih dahulu.

Pada dasarnya pembangunan tersebut dibiayai dari Dana APBN dengan Nominal Anggaran Rp. 1,7 Triliyun yang diprioritaskan untuk "Sisi Manfaat" Sungai di wilayah Manganti (Kota Banjar Jabar-Jawa Tengah) ketika proyek tersebut telah masuk kewilayah Desa Ancol Kecamatan Cineam Kabupaten Tasikmalaya Jawa Barat, meninggalkan masalah pelik yang disinyalir merugikan warga penjual tanah yang terkena dampak pembangunan fisik mega proyek tersebut. Target waktu proyek besar tersebut sekurang-kurangnya memakan waktu 2 Tahun berjalan dengan Program Angaran APBN yang mulai dilaksanakan akhir tahun 2016 yang lalu. Namun, Masyarakat di Desa Ancol merasa dibodohi atas pembebasan lahan tersebut. Pasalnya perbedaan harga pembebasan lahan terdampak bendungan Leuwikeris di Kecamatan Ciamis dengan Kabupaten Tasikmalaya cukup timpang. Harga di Ciamis Rp. 150.000, sementara di Tasikmalaya hanya Rp. 61.000 selisihnya bisa sampai Rp. 90.000. Selain itu juga warga mempermasalahkan pengukuran tanah yang dinilai tidak ada transparansi, tidak ada bukti kwitansi, serta tidak ada mekanisme untuk mengetahui dokumen persetujuan harga penggantian lahan sementara warga dilarang memiliki atau menyalin dokumen tersebut.

Ratusan masyarakat Desa Ancol pun menuntut agar pemerintah pusat bisa menyamakan harga tanah terdampak dendungan Leuwikeris dan segera menyelesaikan hak mereka. Kemudian masyarakat menuntut terutama kepada Pemda Tasikmalaya, BPN, serta Balai Besar Wilayah Sungai (BBWS) Citanduy segera menyelesaikan persoalan ganti rugi. Kemudian masyarakat memblokir akses bendungan, pintu gerbang akan di las sebelum pemerintah menyamakan harga tanah dengan wilayah kabupaten Ciamis. Hal tersebut membuat masyarakat tentu menjadi kecewa karena pembebasan lahan ini tidak ada sosialisasinya tetapi langsung penetapan harga.

Terlebih dengan adanya pembangunan bendungan Leuwikeris di Kabupaten Tasikmalaya diharapkan dapat menimbulkan dampak positif bagi masyarakatnya. Kemudian diharapkan mampu untuk mengatasi masalah-masalah yang sering terjadi di daerah Banjarsari seperti lahan persawahan sering mengalami banjir dan kekeringan. Terlebih bendungan Leuwikeris pun nantinya akan dijadikan sebagai sektor pariwisata. Namun, disisi lain pembangunan bendungan ini justru meninggalkan dampak negatif yang nyata bagi masyarakat sekitar khususnya masyarakat yang tanahnya terkena rencana pembangunan bendungan. Seharusnya dalam suatu pembangunan proyek infrastruktur dengan skala cukup besar seperti bendungan Leuwikeris tersebut diperlukan sebuah forum koordinasi yang diselenggarakan secara berkala antar stakeholder (Pelaksana Proyek, Pemerintah, Masyarakat, Kepolisian, LSM, dan pihakpihak yang terkait lainnya) untuk duduk bersama memahami, menyelesaikan, dan mengantisipasi potensi-potensi masalah termasuk dampak lingkungan yang mungkin timbul akibat pembangunan ini. 


\begin{tabular}{|c|c|c|c|c|}
\hline $\begin{array}{c}\text { JURNAL } \\
\text { KOLABORASI RESOLUSI KONFLIK }\end{array}$ & VOLUME 1 & NOMOR 1 & HALAMAN 1-70 & $\begin{array}{c}\text { ISSN 2655-8823 }(p) \\
\text { ISSN - }(e)\end{array}$ \\
\hline
\end{tabular}

\section{TINJAUAN PUSTAKA \\ Definisi Konflik}

Konflik adalah hubungan antara dua pihak atau lebih (individu atau kelompok) yang memiliki, atau yang merasa memiliki, sasaran-sasaran yang tidak sejalan. Menurut Nardjana (1994) Konflik yaitu akibat situasi dimana keinginan atau kehendak yang berbeda atau berlawanan antara satu dengan yang lain, sehingga salah satu atau keduanya saling terganggu.

\section{Jenis - Jenis Konflik}

Jenis-jenis konflik dibedakan dalam beberapa perspektif. antara lain :

a. Konflik intraindividu. Konflik ini dialami oleh individu dengan dirinya sendiri karena adanya tekanan peran dan ekpektasi di luar berbeda dengan keinginan atau harapannya.

b. Konflik antarindividu. Konflik yang terjadi antarindividu yang berada dalam suatu kelompok atau antarindividu pada kelompok yang berbeda.

c. Konflik antarkelompok. Konflik yang bersifat kolektif antara satu kelompok dengan kelompok lain.

\section{Teori - teori mengenai berbagai penyebab konflik}

a. Teori Hubungan Masyarakat menganggap bahwa konflik disebabkan oleh polarisasi yang terus terjadi, ketidakpercayaan dan permusuhan di antara kelompok yang berbeda dalam suatu masyarakat.

b. Teori Negosiasi Prinsip menganggap bahwa konflik disebabkan oleh posisiposisi yang tidak selaras dan perbedaan pandangan tentang konflik oleh pihakpihak yang mengalami konflik.

c. Teori Kebutuhan Manusia berasumsi bahwa konflik yang berakar dalam disebabkan oleh kebutuhan dasar manusia-fisik, mental, dan sosial yang tidak terpenuhi atau dihalangi. Keamanan, identitas pengakuan, partisipasi, dan otonomi sering merupakan inti pembicaraan.

d. Teori Identitas berasumsi bahwa konflik disebabkan karena identitas yang terancam, yang sering berakar pada hilangnya sesuatu atau penderitaan di masa lalu yang tidak diselesaikan.

e. Teori Kesalahpahaman Antar Budaya berasumsi bahwa konflik disebabkan oleh ketidakcocokan dalam cara-cara komunikasi di antara berbagai budaya yang berbeda.

f. Teori Transformasi Konflik berasumsi bahwa konflik disebabkan oleh masalah-masalah ketidaksetaraan dan ketidakadilan yang muncul sebagai masalah-masalah sosial, budaya dan ekonomi.

\section{METODE RISET}

Penelitian ini termasuk ke dalam jenis penelitian studi literatur. Jenis penelitian studi literatur adalah mencari referensi teori yang relevan dengan kasus atau permasalahan yang ditemukan. Dalam melakukan penelitian ilmiah ini, peneliti melakukan teknik penyusunan secara sistematis untuk memudahkan langkahlangkah yang akan diambil. Peneliti melakukan studi literature pada buku-buku yang membahas mengenai konflik, jurnal dan penelitian yang telah dilakukan berkaitan dengan konflik lahan.

\section{HASIL DAN PEMBAHASAN}

Pada dasarnya pemicu dan penyebab konflik yang terjadi di Desa Ancol Kabupaten Tasikmalaya yaitu adanya suatu kecemburuan dan ketidakadilan yang dirasakan oleh masyarakat Desa Ancol Kabupaten Tasikmalaya dengan masyarakat Kecamatan Ciamis karena masalah penentuan harga pembebasan lahan tanah 
salah satu pihak merasa dirugikan. Hal tersebut terjadi karena pasalnya perbedaan harga pembebasan lahan terdampak Bendungan Leuwikeris di Kecamatan Ciamis dengan Kabupaten Tasikmalaya cukup timpang. Harga di Ciamis Rp. 150.000, sementara di Tasikmalaya hanya Rp. 61.000 selisihnya bisa sampai Rp. 90.000. Sehingga masyarakat Desa Ancol merasa iri terhadap perbedaan harga yang cukup tinggi tersebut. Hal tersebut tersebut tentunya membuat masyarakat Desa Ancol Kabupaten Tasikmalaya merasakan ketidakadilan dari pihak pemerintah. Masyarakat Desa Ancol Kabupaten Tasikmalaya ingin harga tanah permeternya sama dengan harga di Kecamatan Ciamis.

Konflik yang terjadi di desa Ancol tentunya menimbulkan suatu permasalahan yang berdampak kepada masyarakat yang lahannya terdampak oleh bendungan Leuwikeris. Masyarakat mengalami kerugian secara materi karena harga yang dibeli oleh pemerintah memiliki ketimpangan senilai Rp. 90.000 per meternya dengan Kabupaten Ciamis. Kemudian rusaknya lingkungan di sekitarnya banyak sekali hewan buas yang turun ke daerah warga karena habitatnya terganggu dengan dibangunnya bendungan Leuwikeris sehingga mengganggu aktivitas masyarakat disekitar. Kemudian pada akhirnya, masyarakat di Desa Ancol Kabupaten Tasikmalaya memiliki rasa kepercayaan yang berkurang kepada pemerintah yang diakibatkan karena pemerintah tidak memikirkan kepentingan masyarakat tetapi mementingkan kepentingan pemerintah saja. Terlebih lahannya yang terdampak oleh bendungan Leuwikeris tersebut tadinya dijadikan sebagai lahan pertanian dan perkebunan oleh masyarakat desa Ancol tersebut namun pada akhirnya dibeli dengan harga yang tidak sesuai oleh pemerintah. Tentunya, hal tersebut akan menjadi penghambat suatu perekonomian masyarakat Desa Ancol.
Jika meninjau pada teori transformasi konflik menurut Fisher dkk, berasumsi bahwa konflik disebabkan oleh masalahmasalah ketidaksetaraan dan ketidakadilan yang muncul sebagai masalah-masalah sosial, budaya, dan ekonomi. Teori ini memiliki sararan yang ingin dicapai yaitu mengubah berbagai struktur dan kerangka kerja yang menyebabkan ketidaksetaraan dan ketidakadilan, termasuk kersenjangan ekonomi, meningkatkan jalinan hubungan dan sikap jangka panjang diantara pihakpihak yang mengalami konflik, mengembangkan berbagai proses dan sistem untuk mempromosikan pemeberdayaan, keadilan, perdamaian, pengampunan, rekonsiliasi, pengakuan. Maka dapat disimpulkan bahwa konflik yang terjadi di Desa Ancol yaitu masyarakat merasa adanya ketidakaddilan serta ketidaksetaraan mengenai harga tanah yang dibeli oleh pemerintah dengan Kabupaten Ciamis dan akibat ganti rugi yang tidak sesuai dengan keinginan warga. Sehingga hal tersebut menyebabkan timbulnya suatu konflik di Desa Ancol. Konflik pertanahan di mega proyek ini jika dilihat dari sumber penyebabnya adalah ketidakadilan distribusi, Faturochman menyatakan bahwa ketidakadilan distribusi berkait dengan proporsional, pemerataan, kebutuhan, permintaan dan penawaran di pasar, mengutamakan dan menguntungkan orang lain, serta kepentingan pribadi dan kelompok.

Konflik pembebasan lahan pertanahan pembangunan bendungan Leuwikeris ini telah memberi peluang kepada aparat pemerintahan, kemudian aparat keamanan setempat untuk memberikan resolusi konflik sebagai mediator. Adapun bentuk strategi yang digunakan oleh aparat pemerintah dan keamanan setempat adalah berupa social movement menuju ke arah demokrasi yang berkaitan dengan perubahan menuju suatu arah yang dianggap ideal sebagai penggeraknya. Strategi alternatif kedua yang 
dapat digunakan sebagai mediator adalah mengusulkan kompromi antar kedua belah pihak agar konflik tidak berkembang. Kompromi merupakan kemauan untuk berbagi sumber-sumber yang terbatas atau tersedia di antara pihak-pihak yang terlibat dan dapat mengambil posisi tengah antara dimensi yang menyerang dan kerjasama mencari titik temu, yang dilengkapi dengan keahlian memberi motivasi dalam negosiasi dan bergainning (tawar menawar harga tanah), yang tujuannya berupa winwin solution bagi kedua belah pihak yang berkonflik.

\section{KESIMPULAN DAN SARAN}

Konflik pembebasan lahan pertanahan milik masyarakat Desa Ancol Kabupaten Tasikmalaya terkait dengan mega proyek pembangunan bendungan Leuwikeuris saat ini memang belum terselesaikan, hal ini karena bendungan Leuwikeuris tersebut belum selesai dibangun. Walaupun, proses pembangunan bendungan Leuwikeuris tersebut mengalami suatu permasalahan akibat polemik antar pemerintah dan masyarakat Desa Ancol Kabupaten Tasikmalaya proyek tetap berjalan membangun bendungan tersebut. Konflik tersebut dilatarbelakangi oleh kecemburuan, ketidakpuasan serta ketidakadilan yang dirasakan oleh masyarakat, karena lebih banyak dampak negatif yang diterima dari adanya pembangunan bendungan Leuwikeris, kecemburuan sosial antar masyarakat Desa Ancol Kabupaten Tasikmalaya dengan masyarakat Kecamatan Ciamis karena adanya perbedaan harga tanah permeternya yang sangat jauh. Permasalahan sosial di Desa Ancol Kab harus benar-benar diselesaikan dengan tuntas. Pencegahan konflik sejak dini harus segera dilakukan agar tidak terjadi mengarah kepada konflik kekerasan yang akan merugikan semua pihak

Terlebih bendungan Leuwikeris pun nantinya akan dijadikan sebagai sektor pariwisata. Namun, disisi lain pembangunan bendungan ini justru meninggalkan dampak negatif yang nyata bagi masyarakat sekitar khususnya masyarakat yang tanahnya terkena rencana pembangunan bendungan. Seharusnya dalam suatu pembangunan proyek infrastruktur dengan skala cukup besar seperti bendungan Leuwikeris tersebut diperlukan sebuah forum koordinasi yang diselenggarakan secara berkala antar stakeholder (Pelaksana Proyek, Pemerintah, Masyarakat, Kepolisian, LSM, dan pihakpihak yang terkait lainnya) untuk duduk bersama memahami, menyelesaikan, dan mengantisipasi potensi-potensi masalah termasuk dampak lingkungan yang mungkin timbul akibat pembangunan ini.

\section{DAFTAR PUSTAKA}

Basri, Said Hasan. Analisis Pemberantasan Tanah dan Resolusinya di Balik Mega Proyek Jembatan Suramadu. 2013. Tersedia : $\quad$ http://digilib.uinsuka.ac.id/13936/1/Welfare $\% 20 \mathrm{Vol} \% 20$ 2\%20No\%201\%20Januari\%20\%20Juni\%202013\%20CHAPTER\%202. pdf ( diakses pada tanggal 3 April 2018 pukul 10.30 WIB).

Dwiwahyuni, Ida. 2011. Jenis dan Sumber Konflik

Fisher, S. dkk., Mengelola Konflik, Keterampilan dan Strategi Untuk Bertindak. Jakarta: SMK Grafika Desa Putra. 2001.

Indrashi, Hatake. 2012. Bentuk dan Sumber Konflik di Organisasi Pendidikan.

Irawanto, Febri. 2011. Pengertian, Bentuk, Faktor, dan Dampak Konflik.

Ritzer, G. (2012). Teori Sosiologi. Edisi Revisi. Yogyakarta: Pustaka Pelajar.

Winardi. 2007. Manajemen Konflik. Bandung : CV. Mandar Maju. https://www.radartasikmalaya.com/bbwskembali-bebaskan-tanah/. Diakses pada tanggal 2 April 2018 pukul 19.25 WI. 


\begin{tabular}{|c|c|c|c|c|}
\hline JURNAL & NOLUME 1 & NOMOR 1 & HALAMAN 1-70 & $\begin{array}{c}\text { ISSN 2655-8823 }(p) \\
\text { ISSN - }(e)\end{array}$ \\
\hline
\end{tabular}

http://www.liputan6.com/news/read/306318

9/warga-segel-proyek-pembangunan-

bendungan-leuwikeris-tasikmalaya.

Diakses pada tanggal 2 April 2018 pukul 22.00 WIB. http://www.pikiran-rakyat.com/jawabarat/2017/08/14/warga-terdampakbendungan-leuwikeris-desak-bupatiturun-tangan-407336. Diakses pada tanggal 3 April 2018 pukul 06.30 WIB. 